\title{
INTENSITAS SERANGAN HAMA PENGGEREK BUAH KAKAO (Conopomorpha cramerella Snell) DAN KEHILANGAN HASIL KAKAO (Theobroma cacao) DI KECAMATAN PEUNARON
}

\author{
Fajar Pratama ${ }^{1}$, Cut Mulyani ${ }^{2}$, Boy Riza Juanda ${ }^{2}$ \\ ${ }^{I}$ Mahasiswa Program Studi Agroteknologi, Fakultas Pertanian, Universitas Samudra \\ ${ }^{2}$ Dosen Program Studi Agroteknologi, Fakultas Pertanian, Universitas Samudra \\ Email :fajarpratama110@gmail.com
}

\begin{abstract}
ABSTRAK
Tujuan penelitian ini untuk mengetahui pengaruh intensitas serangan hama penggerek buah kakao dan kehilangan hasil kakao di Kecamatan Peunaron. Penelitian ini menggunakan metode survei, penentuan sampel dilakukan secara "Purposive". dilaksanakan di tiga desa yaitu Desa Peunaron Lama, Peunaron Baru dan Bukit Tiga mulai dari bulan Maret 2020 sampai bulan April 2020. Pada masing-masing kriteria kebun yang diamati, persentase dan intensitas serangan hama PBK menunjukan tingkatan yang berbeda. hal ini disebabkan oleh tinggi rendahnya kelembaban kebun yang memicu tingginya aktivitas hama PBK. Rerata persentase serangan dan intensitas serangan hama PBK tertinggi yaitu pada kebun yang tidak dirawat dengan nilai masing-masing $49 \%$ dan 23,9\% yang terendah yaitu pada kebun yang dirawat secara intensif dengan nilai masing-masing $16,5 \%$ dan 4,6\%. Rerata intensitas serangan pada seluruh kebun yang diamati yaitu 20,9\%. Sedangkan kehilangan hasil akibat meningkatnya intensitas serangan hama PBK mencapai $170,34 \mathrm{Kg} / \mathrm{Ha} / \mathrm{Tahun}$.
\end{abstract}

Kata Kunci : Kakao, Penggerek Buah Kakao, Pengendalian Hama Terpadu

\section{PENDAHULUAN}

Kakao (Theobroma cacao, L) merupakan salah satu komoditas andalan nasional dan berperan penting bagi perekonomian Indonesia, terutama dalam penyedian lapangan kerja, sumber pendapatan petani, dan sumber devisa bagi negara (Lukito $d k k$., 2010). Perkembangan tanaman kakao dapat dilihat dari segi luas areal maupun sumbangannya kepada negara sebagai komoditas ekspor. Pengekspor biji kakao pertama diduduki oleh Pantai Gading dan posisi kedua diduduki oleh Ghana kemudian disusul oleh Indonesia Tadya dkk, 2018. Produksi kakao Indonesia pada tahun 2015 yaitu 593.331 ton, selanjutnya pada tahun 2016 meningkat menjadi 658.339 ton kemudian mengalami penurunan pada tahun 2017 menjadi 590.684 ton dan pada tahun 2018 meningkat kembali menjadi 593.833 ton (Direktorat Jendral Perkebunan, 2019).

Kementan (2019), menyebutkan bahwa Indonesia memiliki sentra perkebunan kakao, 10 provinsi panghasil kakao terbesar antara lain Sulawesi Tengah (100.702 ton), Sulawesi Selatan (100.567 ton) Sulawesi Tenggara (93.301 ton), Sulawesi Barat (54.710 ton), Sumatera Barat (46.151 ton), Lampung (35.047 ton), Jawa Timur (28.270 ton), Aceh (27.364 ton), Sumatera Utara (24.819 ton), dan Nusa Tenggara Timur (13.125 ton). Pada tahun 2019 Badan Pusat Statistik menyebutkan bahwa luas perkebunan kakao di provinsi Aceh yaitu 101.298 ha dengan produksi sebanyak 27.364 ton kakao per tahun.

Kabupaten Aceh Timur merupakan daerah penghasil kakao di Provinsi Aceh dan menjadikan kakao menjadi komoditas andalan disamping komoditi lainya seperti padi, kelapa dan kelapa sawit. Menurut data BPS Aceh Timur, luas total dari perkebunan kakao seluas 12.821 ha dimana Ranto 
Peureulak menjadi kecamatan dengan luasan terbesar yaitu 3.743 ha dilanjutkan dengan Peunaron dengan luas 1.628 ha dan diikuti oleh kecamatan-kecamatan lain di Aceh Timur. BPS Aceh Timur juga menyebutkan total produksi kakao di Kabupaten Aceh Timur pada tahun 2018 sebanyak 6.411 ton/tahun serta rata-rata produktivitas $750 \mathrm{~kg} /$ tahun. (BPS Aceh Timur, 2019).

Hayata (2017) menyatakan bahwa akibat serangan penggerek buah kakao (Conopomorpha cramerella Snella) dapat menurunkan produksi sampai $80 \%$ dan kerusakan biji sampai $82 \%$. Gejala serangan PBK mengakibatkan buah kakao berwarna agak jingga atau pucat keputihan, buah menjadi lebih berat dan bila diguncangkan tidak terdengar suara ketukan antara biji dan dinding buah. Hal itu terjadi karena timbulnya lendir dan kotoran pada daging buah dan rusaknya biji-biji di dalam buah.

Hama Penggerek Buah Kakao menyerang semua fase buah yaitu buah muda, buah dewasa dan buah matang. Gejala serangan pada buah muda ditandai dengan permukaan kulit buah yang terserang terlihat bercak besar berwarna kuning. Jika buah-buah yang menunjukkan gejala tersebut dibelah, kulit buah dan tempat masuknya larva serta saluran (plasenta) biji tempat larva mengambil makanan terlihat berwarna coklat akibat serangan larva. Sedangkan daging buah masih tetap berwarna putih. Pada serangan berat bagian dalam buah berwarna coklat kehitaman. Berdasarkan hasil wawancara dengan petani di Kecamatan Peunaron bahwa hama PBK yang menyerang tanaman kakao di perkebunan rakyat di Kecamatan Peunaron Kabupaten Aceh Timur merupakan hama utama yang menyebabkan turunnya produksi biji kakao. Hal ini disebabkan larva penggerek buah kakao yang menyerang buah kakao yang menyebabkan kerusakan biji kakao yang memiliki nilai ekonomis yang tinggi sehingga serangan hama ini cukup merugikan. (Hayata, 2017).

Diketahui Kecamatan Peunaron memiliki potensi pengembangan kakao di Kabupaten Aceh Timur. Sementara data valid yang menunjukkan mengenai tingkat serangan hama penggerek buah kakao di daerah ini belum tersedia, untuk itu dalam mengupayakan strategi pengendalian hama penggerek buah kakao dan jumlah kehilangan hasil akibat serangan penggerek buah kakao maka dilakukan penelitian dengan judul "Intensitas Serangan Penggerek Buah Kakao (Conopomorpha cramerella Snella) dan Kehilangan Hasil Tanaman Kakao (Theobroma cacao) di Kecamatan Peunaron Kabupaten Aceh Timur".

\section{METODE PENELITIAN}

Penelitian ini dilakukan di beberapa desa yaitu desa Peunaron Lama, Peunaron Baru dan Bukit Tiga Kecamatan Peunaron, Kabupaten Aceh Timur selama 2 (dua) bulan, yang dimulai pada bulan Maret 2020 sampai dengan April 2020. Penentuan lokasi penelitian dilakukan secara 'purposive', yaitu penentuan lokasi yang dipilih secara langsung atau sengaja dengan alasan bahwa pada lokasi tersebut merupakan sentra perkebunan kakao di Kecamatan Peunaron Kabupaten Aceh Timur yang didukung dengan hasil observasi lapangan dan wawancara langsung pada survei pendahuluan.

Lokasi sampel untuk mengetahui intensitas serangan hama PBK dan potensi kehilangan hasil dipilih pada kebun yang mempunyai kriteria sebagai berikut:

1. Kebun yang tidak dirawat (tidak dilakukan perawatan, kebun kakao kondisinya seperti hutan).

2. Kebun dirawat seadanya (perawatan kebun dilakukan insidentil, waktunya tidak teratur)

3. Kebun yang dirawat intensif (kebun kakao dilakukan perawatan dengan memberikan pupuk, pemangkasan, dilakukan sambung samping pada pohon kakao yang sudah melewati masa produktif), dan

4. Kebun yang mempraktekkan pengendalian hama terpadu (PHT) (binaan dari NGO Swiss Contact, Dinas Perkebunan dan Badan Penyuluhan). 
Pengambilan sampel dilakukan pada semua kriteria kebun dimasing-masing desa. Total keseluruhan sampel yang diambil berjumlah 12 sampel. Apabila pada desa tersebut ada yang tidak memiliki salah satu dari keempat kriteria perawatan yang berbeda, maka sampel yang diambil hanya dari kriteria perawatan kebun yang ada. Pada masing-masing kriteria kebun pengambilan buah kakao pada setiap desa yang terserang hama PBK yaitu $10 \%$ dari total populasi cara pengambilan sampel buah kakao adalah dengan pola diagonal (X). Buah yang diambil sebagai sampel adalah buah yang akan dipanen (sudah masak) dan mempunyai kondisi homogen yang dilihat dari varietas, umur dan luas kebun. Pengambilan buah kakao dilakukan sebanyak 2 kali interval panen.

\section{Metode Pengukuran Serangan Hama PBK}

Untuk mengukur tinggi kerusakan dan kehilangan hasil akibat serangan penggerek buah kakao pada buah kakao, dilakukan perhitungan terhadap persentase serangan (PS), intensitas serangan (IS), dan persentase kehilangan hasil (Y), Penentuan persentase serangan ini dihitung dengan menggunakan formula yang dikemukakan oleh Pedigo dan Buntin (2003) sebagai berikut :

$$
P=\frac{A}{B} \times 100 \%
$$

Keterangan :

$\mathrm{P}=$ Persentase buah terserang

A = Jumlah buah yang terserang

$\mathrm{B}=$ Jumlah buah yang diamati

Intensitas serangan (IS) adalah suatu besaran yang menggambarkan tingkat kerusakan buah. Pengukuran intensitas serangan penggerek buah kakao menggunakan 4 kategori berdasarkan banyaknya biji lengket pada setiap buah yang diamati, yaitu sehat, ringan (R), sedang (S), berat (B). Perhitungan intensitas serangan penggerek buah kakao menggunakan rumus yang dikemukakan oleh Sulistyowati dkk. (2007) sebagai berikut :

$$
\mathrm{IS}=[(1 \mathrm{R}+3 \mathrm{~S}+9 \mathrm{~B})] / \mathrm{AT}
$$

\section{Keterangan:}

IS : intensitas serangan (\%)

$\mathrm{R} \quad$ : jumlah buah terserang ringan

S : jumlah buah terserang sedang

B : jumlah buah terserang berat

A : nilai pembobot tertinggi

$\mathrm{T} \quad$ : jumlah buah yang diamati 
Kategori tingkat kerusakan buah akibat serangan hama PBK dapat dilihat pada tabel 1 .

Tabel 1. Kategori Tingkat Kerusakan Buah Akibat Serangan Hama PBK

\begin{tabular}{ccl}
\hline Nilai pembobot & $\begin{array}{l}\text { Kategori tingkat } \\
\text { kerusakan buah }\end{array}$ & \multicolumn{1}{c}{ Kriteria biji lengket } \\
\hline 0 & Bebas & Tidak ada biji lengket. \\
1 & Ringan & $\begin{array}{l}\text { Terdapat biji lengket }<10 \% \text { tetapi semua biji masih dapat } \\
\text { dikeluarkan dari kulit buah. } \\
\text { Terdapat biji lengket antara } 10 \%-50 \%, \text { sebagian besar biji masih } \\
\text { dapat dikeluarkan dari kulit buah. } \\
\text { Terdapat biji lengket }>50 \%, \text { dan sebagian besar biji tidak dapat } \\
\text { dikeluarkan dari kulit buah. }\end{array}$ \\
\hline
\end{tabular}

Sumber: Sulistyowati dkk. (2007)

Setelah diketahui intensitas serangan, maka dibuat tabel pengamatan serangan hama PBK. Adapun untuk menentukan kehilangan hasil kakao akibat serangan hama PBK menggunakan regresi dengan model matematis.

$$
\mathrm{Y}=\mathrm{a}+\mathrm{bX}
$$

Dimana :

$\mathrm{Y}=$ Kehilangan hasil kakao

$\mathrm{a}=$ Konstanta

$\mathrm{b}=$ Koefesien variabel $\mathrm{X}$

$\mathrm{X}=$ Intensitas Serangan $(\%)$

\section{HASIL DAN PEMBAHASAN}

\section{Kondisi Lokasi Penelitian}

Kecamatan Peunaron terletak di Kabupaten Aceh Timur Provinsi Aceh, wilayah ini memiliki luas areal perkebunan sebesar $6213 \mathrm{Ha}$. Petani merupakan pekerjaan yang mendominasi di wilayah Kecamatan Peunaron dengan komoditas utama perkebunan kelapa sawit, kakao dan diikuti dengan komoditas lainnya seperti karet, pinang, kelapa. Total luas perkebunan kakao yang terdapat di Kecamatan Peunaron ialah $1628 \mathrm{Ha}$ dengan total produksi 604,04 Kg/Ha/Tahun (BPS Kabupaten Aceh Timur, 2019).

Dari hasil survei yang telah dilakukan di ketiga desa yang menjadi lokasi penelitian menunjukkan bahwa rata-rata telah menjadi petani kakao \pm 10 tahun. Jenis bibit kakao yang ditanam oleh petani adalah forastero dan trinatario dengan jarak tanam yang digunakan $4 \mathrm{~m} \mathrm{x} 4 \mathrm{~m}$. Tanaman pelindung yang digunakan ialah tanaman pinang dan lamtoro. Luas kebun yang dimiliki oleh petani rata-rata 1 ha. Perawatan tanaman kakao seperti pemangkasan, pemupukan dan sanitasi yang dilakukan petani belum optimal dikarenakan jarak perkebunan yang jauh dengan pemukiman.

Berdasarkan hasil observasi dan wawancara dengan petani, hama penggerek buah kakao menjadi hama utama yang menyerang perkebunan kakao di wilayah Kecamatan Peunaron. Hama dan penyakit yang juga terdapat di wilayah ini diantaranya hama kepik penghisap buah dan penyakit busuk buah yang turut menurunkan produksi kakao serta didukung dengan umur tanaman yang sudah mulai berumur tua, kurangnya pengetahuan tentang perawatan tanaman kakao sehingga pemeliharaan yang dilakukan oleh petani belum maksimal. Sebaran dari hama PBK merata di setiap kebun yang 
dilakukan penelitian yang membuat kualitas dan kuantitas dari biji kakao menjadi rendah. Karena permasalahan yang ditimbulkan oleh hama PBK juga membuat sebagian petani mulai mengganti tanaman kakao menjadi tanaman kelapa sawit yang dinilai lebih mudah dalam perawatan serta nilai ekonominya lebih menguntungkan.

Petani kakao di Kecamatan Peunaron melakukan pengelolaan kebun kakao dengan berbekal ilmu dasar yang diturunkan secara turun-temurun dari petani lainnya serta mendapatkan ilmu dari pelatihan-pelatihan yang didapatkan melalui Pelaksana Penyuluh Lapangan dari Dinas Pertanian dan Perkebunan dan beberapa NGO (Non-Govermental Organization) seperti Swiss Contact dan Keumang mengenai tata cara budidaya kakao yang baik dan benar seperti pemupukan, pemangkasan, peremajaan sambung samping dan pengendalian hama penyakit terutama hama Penggerek Buah Kakao. Namun tidak banyak petani yang benar-benar menerapkan ilmu yang didapatkan sehingga pemeliharaan dan pengelolaan tanaman kakao belum optimal seperti yang diharapkan.

\section{Persentase Serangan Hama PBK}

Keberadaan hama penggerek buah kakao pada masing-masing desa di Kecamatan Peunaron dianalisa berdasarkan persentase serangan hama PBK. Persentase serangan penggerek buah kakao diamati pada saat pemanenan buah dengan melihat gejala serangan yang telah disebutkan oleh Karmawati, dkk (2010) yaitu ditandai dengan kulit buah berwarna pudar dan timbul belang berwarna jingga serta akan tampak berwarna hitam, biji-biji lengket satu sama lainnya berwarna hitam, keriput dan ringan.

Tabel 2. Persentase Serangan Hama PBK Di Kecamatan Peunaron (\%)

\begin{tabular}{ccccc}
\hline \multirow{2}{*}{ Desa Sampel } & Tidak dirawat & Rawat Seadanya & Rawat Intensif & $\begin{array}{c}\text { Mempraktik- } \\
\text { kan PHT }\end{array}$ \\
\cline { 2 - 5 } & 52,5 & 45 & - & - \\
Peunaron Lama & 42 & 52 & - & - \\
Peunaron Baru & 52,5 & 33 & 16,5 & 20,5 \\
Bukit Tiga & 49 & 43,3 & 16,5 & 20,5 \\
\hline Rataan & & &
\end{tabular}

Sumber : Data Primer Hasil Survei Lapangan 2020

Berdasarkan hasil pengamatan diketahui terdapat perbedaan persentase serangan PBK. Persentase serangan hama PBK yang berada pada kriteria kebun tidak terawat yaitu $42 \%-52,5 \%$ dengan nilai rata-rata 49\%. Serangan PBK paling tinggi dijumpai di kriteria kebun yang sama sekali tidak terawat di Desa Peunaron Lama dan Bukit Tiga yakni 52,5 \%. Menurut Azim dkk (2016), bahwa pada tanaman yang ternaungi dan terlindungi sinar matahari aktivitas imago PBK tinggi, Imago PBK pada siang hari istirahat pada cabang-cabang terlindungi dari sinar matahari, sedangkan penyebarannya dibantu oleh angin.

Tinggi dan rendahnya persentase serangan PBK dipengaruhi oleh berbagai faktor, seperti panen tidak rutin, kondisi lahan, terutama keberadaan serasah dan kulit sisa panen. Menurut Sulistyowati (2003), panen pada buah masak yang disertai dengan kegiatan sanitasi dapat menekan populasi hama PBK. Hal ini disebabkan pada buah masak awal, larva PBK masih berada di dalam buah, sehingga akan mati jika kulit buah dan plasenta langsung dibakar atau dibenamkan kedalam tanah. Hal ini juga menunjukkan bahwa panen rutin dan pembersihan lahan dari kulit buah sisa panen dapat memutuskan siklus hidup PBK. Menurut Sulistyowati dan Wirdyadiputra (2010), sisa daun bekas pangkasan dan kulit buah bekas panen dapat menjadi tempat PBK, sehingga populasi PBK pada kebun yang tidak disanitasi lebih tinggi dibandingkan dengan kebun yang dilakukan sanitasi. 


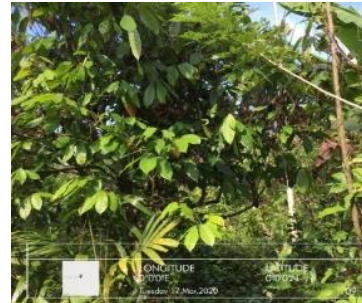

(a)

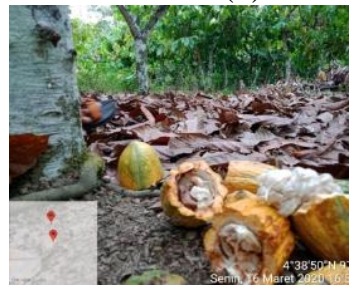

(c)

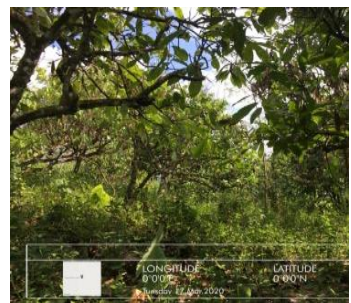

(b)

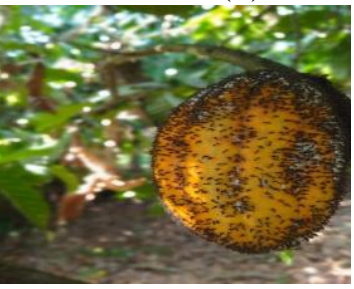

(d)

Gambar 1. Kriteria Kebun : (a) Tidak Dirawat, (b) Dirawat Seadanya, (c) Dirawat Intensif, (d) Mempraktikkan PHT

Kriteria kebun yang dirawat seadanya memiliki persentase serangan hama PBK berkisar antara $33 \%-52 \%$ dengan nilai rata-rata serangan $43,3 \%$. pada kriteria kabun yang dirawat seadanya petani melakukan perawatan dengan waktu yang tidak teratur tergantung keinginan petani bukan berdasarkan kebutuhan perawatan yang dibutuhkan oleh tanaman kakao. Pemangkasan dilakukan paling sedikit dua tahun sekali, sehingga cahaya dapat menembus ke dalam pertanaman kakao dan sirkulasi udara dalam pertanaman kakao akan lebih baik sehingga menjadikan kondisi tersebut menjadikan kondisi yang tidak sesuai untuk perkembangan populasi hama PBK. (Sulistyowati, dkk., 2002).

Persentase serangan terendah mencapai $16,5 \%$ dikarenakan telah melakukan perawatan tanaman kakao dengan intensif dan pengelolaan yang baik, yaitu kebersihan lahan terjaga, panen rutin, pemangkasan rutin dan teratur, serta pengendalian organisme penggangu tanaman secara berkala.

\section{Intensitas Serangan Hama PBK}

Pengamatan terhadap intensitas serangan hama PBK di Kecamatan Peunaron, Kabupaten Aceh Timur dapat dilihat pada Table 3 .

Tabel 3. Intensitas Serangan Hama PBK di Kecamatan Pante Bidari (\%).

\begin{tabular}{cccccc}
\hline & \multicolumn{5}{c}{ Kriteria Kebun } \\
\cline { 2 - 5 } Desa Sampel & Tidak dirawat & Rawat Seadanya & $\begin{array}{c}\text { Rawat } \\
\text { Intensif }\end{array}$ & $\begin{array}{c}\text { Mempraktik-kan } \\
\text { PHT }\end{array}$ & Rerata \\
\hline Peunaron Lama & 24,6 & 18,8 & - & - & 21,7 \\
Peunaron Baru & 21,1 & 23,8 & - & - & 22,45 \\
Bukit Tiga & 26 & 11,3 & 3,9 & 4,6 & 18,64 \\
\hline Rerata & 23,9 & 17,9 & 3,9 & 4,6 & 20,9 \\
\hline
\end{tabular}

Sumber : Data Primer Hasil Survei Lapangan 2020

Tabel diatas menjelaskan bahwa intensitas serangan tertinggi terdapat pada kriteria kebun tidak terawat yaitu 21,1\%-26\%. intensitas serangan tertinggi di Desa Bukit Tiga mencapai 26\%. intensitas serangan terkecil adalah pada desa yang memiliki kebun yang telah merawat secara intensif yakni 3,9\% di Desa Bukit Tiga. Hal ini berkaitan dengan tindakan kultur teknis berupa pemangkasan, sanitasi kebun, dan panen yang dilakukan secara rutin. Intensitas serangan PBK pada buah kakao 
sangat ditentukan oleh kerusakan biji kakao. Fluktuasi banyaknya tanaman terserang dan buah terserang bergantung pada kegiatan pengendalian yang dilakukan oleh para petani.

Pada buah yang masih muda, biji melekat pada kulit buah dan melekat satu sama lain, sedangkan pada buah matang tidak menimbulkan kerusakan pada biji tapi dapat menurunkan mutu biji. Tingkat serangan hama Penggerek Buah Kakao yang diamati dapat dilihat pada Gambar 2.

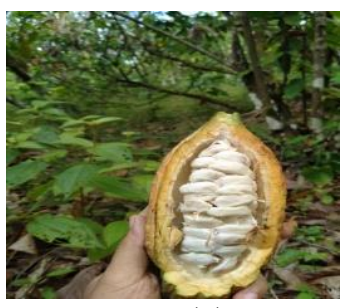

(a)

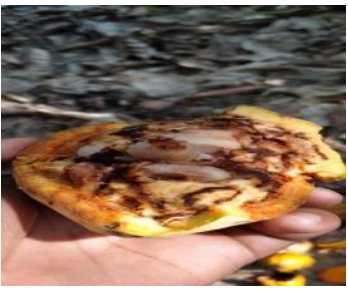

(c)

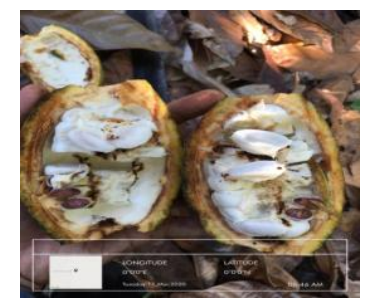

(b)

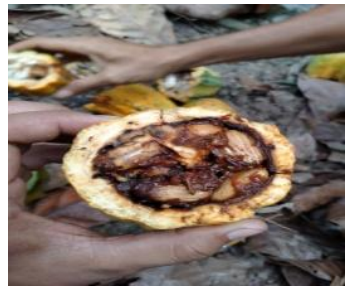

(d)

Gambar 2.Tingkat Serangan Buah : (a) Tidak Terserang, (b) Ringan, (c) Sedang, dan (d) Berat.

Hasil pengamatan yang telah dilakukan pada ketiga desa menunjukkan bahwa rerataan intensitas serangan hama PBK pada semua kreteria kebun tergolong dalam kategori serangan rendah, dimana tingkat serangan tertinggi terdapat di Desa Peunaron Baru yaitu mencapai 22,45\%, di Desa Peunaron Lama $21,7 \%$ dan di Desa Bukit Tiga yang terendah mencapai 18,64\%. sedangkan rerataan intensitas serangan hama PBK pada keseluruhan sampel kebun yang telah diamati adalah 20,9\%.

Menurut Karmawati, dkk (2010) intensitas serangan hama PBK dihitung berdasarkan skor tingkat kerusakan biji, semakin tinggi jumlah buah dengan skor tingkat serangan tertentu maka intensitas serangan pun meningkat. Serangan pada buah ditandai dengan memudarnya warna kulit buah, muncul warna belang hijau kuning atau merah jingga. Apabilah buah digoncang tidak berbunyi. apabila buah dibelah, terlihat biji yang berwarna hitam dan melekat satu sama lain.

\section{Kehilangan Hasil Kakao}

Kehilangan hasil yang disebabkan oleh serangan hama PBK, dilakukan dengan menganalisis data-data yang telah terkumpul dan menggunakan metode regresi linier untuk menghubungkan produksi dengan intensitas serangan. pada Tabel 4 dapat dilihat analisis regresi kehilangan hasil kakao di Kecamatan Peunaron.

Luas sampel kebun yang telah diamati adalah 1 ha, rata-rata produksi seluruh sampel kebun yaitu $340,6 \mathrm{Kg} / \mathrm{Ha} /$ tahun dan rata-rata intensitas serangannya $16,7 \%$. Kurva berwarna merah adalah variabel $\mathrm{X}$ atau intensitas serangan dan kurva berwarna biru adalah variabel $\mathrm{Y}$ atau kehilangan hasil kakao, ditemukan nilai intercept $(a)=512,20$ dan nilai slop $(b)=-10,2$ sehingga model regresi liniernya adalah $\mathrm{Y}=512,20-10,2 \mathrm{X}$. hubungan antara intensitas serangan dengan kehilangan hasil akibat serangan PBK dapat dilihat pada Gambar 3 
Tabel 4. Analisis Regresi Linier Kehilangan Hasil Kakao

\begin{tabular}{lllll}
\hline Desa Sampel & Kriteria Kebun & Luas (Ha) & $\begin{array}{l}\text { Produksi } \\
(\text { Kg/Tahun })\end{array}$ & $\begin{array}{l}\text { Intensitas } \\
\text { Serangan }(\%)\end{array}$ \\
\hline \multirow{3}{*}{ Peunaron Lama } & Tidak dirawat & 1 & 250 & 24,6 \\
& Rawat Seadanya & 1 & 300 & 18,8 \\
& Intensif Mempraktikkan PHT & - & - & - \\
Peunaron Baru & Tidak dirawat & 1 & - & 21,2 \\
& Rawat Seadanya & 1 & 300 & 23,8 \\
& Intensif & - & 375 & - \\
Bukit Tiga & Mempraktikkan PHT & - & - & - \\
& Tidak dirawat & 1 & - & 26,0 \\
& Rawat Seadanya & 1 & 200 & 11,3 \\
\hline Rata-rata & Intensif & 1 & 300 & 3,9 \\
\hline Sumpraktikkan PHT & 1 & 450 & 4,6 \\
\hline
\end{tabular}

Sumber : Data Primer Hasil Survei Lapangan 2020

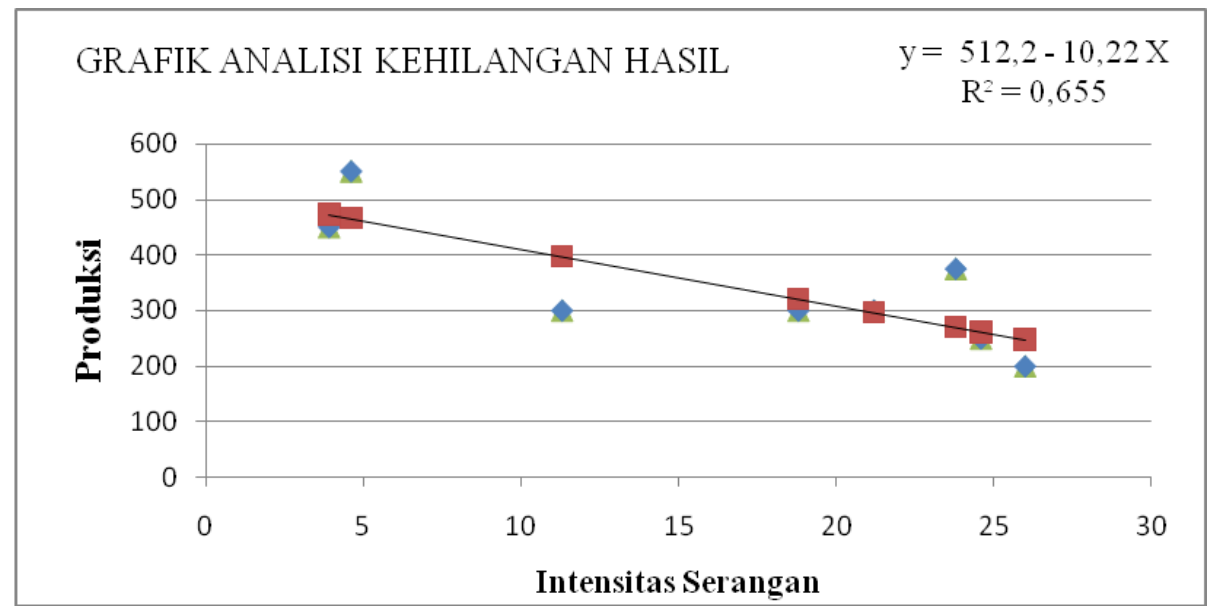

Gambar 3.Grafik Pengaruh Intensitas Serangan Hama PBK terhadap Kehilangan Hasil Kakao

Dari hasil Regresi linier dapat dilihat tanda negatif pada nilai b menunjukkan bahwa antara variabel dependent/terikat berjalan dua arah, dimana setiap peningkatan variabel independent/bebas akan diikuti dengan variabel terikatnya, dan sebaliknya. Jadi semakin tinggi intensitas serangan maka kehilangan hasil akan semakin tinggi dimana setiap terjadi peningkatan intensitas serangan sebanyak $1 \%$ maka akan terjadi kehilangan hasil sebanyak 10,2 Kg. Model regresi liniernya yaitu Y = 512,20 10,2 X. secara umum hasil penelitian di Kecamatan Peunaron diperoleh intensitas serangan rata-rata $16,7 \%$ dengan estimasi kehilangan hasil $170,34 \mathrm{Kg} / \mathrm{Ha} /$ tahun.

Serangan hama PBK berdampak pada hilangnya hasil tanaman kakao, menurut Limbongan (2011) hal ini dikarenakan buah yang terserang hama PBK akan mengalami kerusakan pada biji seperti lengket, dan kandungan lemaknya menurun. 
Serangan pada buah kakao muda mengakibatkan kehilangan hasil yang lebih besar karena buah akan mengalami kerusakan dini dan tidak dapat dipanen. Kerugian yang disebabkan oleh PBK merupakan resultane dari turunnya berat dan mutu produk serta meningkatnya biaya panen karena pemisah biji sehat dari biji yang rusak memerlukan waktu yang lama (Muliani dan Isnaini 2018).

\section{KESIMPULAN DAN SARAN}

\section{Kesimpulan}

1. Pada masing-masing kriteria kebun, persentase dan intensitas serangan hama PBK yang dilakukan selama dua kali dengan interval waktu seminggu sekali menunjukan tingkatan yang berbeda. Tinggi dan rendahnya persentase serangan disebabkan oleh berbagai faktor, seperti panen tidak rutin, kondisi lahan, terutama keberadaan serasah dan kulit sisa panen.

2. Serangan PBK paling tinggi dijumpai di kriteria kebun yang sama sekali tidak terawat di desa Peunaron Lama dan Bukit Tiga yakni 52,5\%, sedangkan persentase serangan PBK paling rendah dijumpai di desa Bukit Tiga yakni 16,5\%.

3. Kehilangan hasil akibat meningkatnya intensitas serangan hama PBK di Kecamatan Peunaron mencapai $170,34 \mathrm{Kg} / \mathrm{Ha} /$ tahun atau $50,01 \%$ dari $340,6 \mathrm{Kg} / \mathrm{Ha} /$ Tahun produksi rata-rata kakao.

\section{Saran}

1. Perlu dilakukan penelitian lanjutan secara berkala dengan ruang lingkup yang lebih luas untuk memantau perkembangan tingkat serangan hama PBK di Kecamatan Peunaron.

2. Perlu dilakukan perawatan perkebunan kakao secara intensif seperti pemangkasan teratur, pemupukan tepat, dan panen tepat waktu rutin ialah upaya untuk menekan aktivitas serangan PBK yang dapat menyebabkan kehilangan hasil.

\section{DAFTAR PUSTAKA}

Azim, S. F., Daisy, S. K., Noni, N. W., 2016. Kerusakan Biji Kakao Oleh Hama Penggerek Buah Kakao (Conopomorphe cramerella Snellen) Pada Pertanaman Kakao di Desa Muntoi Dan Solimandungan. Skripsi. Program Studi Agroekoteknologi, Jurusan Hama dan Penyakit Tumbuhan Universitas Sam Ratulangi, Manado

Badan Pusat Statistik Kabupaten Aceh Timur. 2019. Kabupaten Aceh Timur Dalam Angka 2019. Aceh Timur.

Badan Pusat Statistik Kabupaten Aceh Timur. 2019. Kecamatan Peunaron Dalam Angka 2019. Aceh Timur.

Direktorat Jenderal Perkebunan. 2019. Kakao, Statistik Perkebunan. Direktorat Jenderal Perkebunan. Jakarta.

Hayata. 2017. Tingkat Serangan Hama Penggerek Buah Kakao (Conopomorpha Cramerella Snell.) (Lepidoptera: Gracillaridae) Di Desa Betung Kecamatan Kumpeh Ilir Kabupaten Muaro Jambi. Jurnal Media Pertanian. Fakultas Pertanian Universitas Batanghari. Jambi.

Karmawati, E., Mahmud, Z., Syakir, M., Munarso, J., Ardana, K., Rubiyo. 2010. Budidaya dan Pasca Panen Kakao. Pusat Penelitian dan Pengembangan Perkebunan Republik Indonesia, Bogor.

Kementerian Pertanian. 2019. Outlook Kakao.: Pusat Data dan Sistem Informasi Pertanian, Kementrian Pertanian. Jakarta 
Limbongan, J. 2011. Karakteristik Morfologis dan Anatomis Klon Harapan Tanah Penggerek Buah Kakao Sebagai Sumber Bahan Tanam. Balai Pengkajian Teknologi Pertanian Sulawesi Selatan. Jurnal Litbang Pertanian. Makassar. 31 (1) : 25

Lukito. Mulyono. Tetty. Hadi dan Nofiandi. 2010. Budidaya Kakao. Pusat Penelitian Kopi dan Kakao Indonesia. Jakarta. 298 hal

Muliani, S., dan Isnaini, J. L. 2018. Intensitas Serangan Hama Penggerek Buah Kakao ( Conomorpha cramerella Snellen. ) di Kecamatan Marioriwawo Kabupaten Soppeng. Jurnal Ilmiah Budidaya dan Pengelola Tanaman Perkebunan. Soppeng.

Pedigo, L.P. dan Buntin, G.D. 2003. Handbook Of Sampling Methods For Arthropods In Agriculture. CRC Press London-Tokyo. 714 pp.

Sulistyowati E, dan Wiryadiputra, S. 2010 Hama Utama Kakao dan Pengendalian. Buku pintar Budidaya Kakao. Pusat Penelitian Kopi dan Kakao Indonesia. Jakarta: Agromedia Pustaka

Sulistyowati, E., Sri, S., Wiryadiputra, S., Junianto dan Y.D. Saidi. 2002. Pengenalan dan Pengendalian Hama Penyakit Tanaman Kakao. Puslitkoka. Jember, Jawa Timur

Sulistyowati., E. 2003. Pengaruh Serangan Hama Penggerek Buah kakao (PBK) Terhadap Mutu Biji Kakao. Warta Pusat Penelitian Kopi dan Kakao, 15 : 29-36

Sulistyowati., E. Mufrihati, E., dan Wardani, S. 2007. Integrated Pest Management of Cocoa Pod Borer in Indonesia. Paper Presented at USDA-ARS Seminar on 22 February 2007, Beltsville, Maryland.

Tadya Aulia Utami, Suharyono, Yulianto Edy. 2018. Analisis Daya Ekspore Biji dan Produk Olahan Kakao Indonesia (Periode 2012-2016). Skripsi. Fakultas Ilmu Administrasi, Universitas Brawijaya. Malang. 